\title{
Microstructural and Electrochemical Characterization of Environmentally Friendly Conversion Layers on Aluminium Alloys
}

\author{
Luis Enrique M. Palomino, João Fábio W. de Castro, Idalina V. Aoki and Hercílio G. de Melo* \\ Departamento de Engenharia Química, Universidade de São Paulo, Av. Prof. Luciano Gualberto, Travessa 3 - 380, \\ Cidade Universitária "Armando de Salles Oliveira”, 05508-900 São Paulo - SP, Brazil
}

\begin{abstract}
Camadas de conversão ricas em Ce têm sido investigadas como possíveis substitutas às camadas de cromo na proteção contra a corrosão de ligas de alumínio. Neste trabalho a microestrutura e o comportamento eletroquímico da liga de alumínio 2024 com e sem camada de conversão de Ce foram investigados utilizando MEV-EDS e EIE. Resultados de EDS mostraram que a presença de partículas de $\mathrm{Cu}$ depositadas sobre a superfície da liga estimula a formação da camada de conversão aumentando a intensidade dos picos de Ce no espectro EDS. Os experimentos de EIE mostraram que a presença da camada de conversão aumenta o valor da impedância, e que a evolução das características da camada pode ser seguida pelas mudanças que ocorrem no ângulo de fases em alta freqüência. As curvas potentiodinâmicas mostraram que a proteção conferida pela camada de conversão deve-se ao bloqueio da reação de redução do oxigênio.
\end{abstract}

Cerium conversion layers (CeCL) have been investigated as a replacement for chromium conversion layers to protect $\mathrm{Al}$ alloys against corrosion. In this work the microstructure and the electrochemical behaviour of aluminium alloy 2024 with and without CeCL were investigated using, respectively, SEM-EDX and EIS. EDX results have shown that the presence of dispersed plated $\mathrm{Cu}$ particles on the alloy surface enhances the formation of the CeCL increasing the intensity of Ce peaks in the EDX spectra. EIS measurements on conversion-coated samples have shown that the presence of the layer increases the impedance, and that its presence is detected by the presence of a high frequency time constant. Results of potentiodynamic experiments have shown that the corrosion protection afforded by the conversion layer is due to the hindrance of the oxygen reduction reaction and that the pitting potential of the alloy is not changed.

Keywords: AA2024, EIS, EDX, cerium conversion layer, Cu content

\section{Introduction}

Aluminium alloys of the 2000 series, $\mathrm{Al}-\mathrm{Cu}$, are one of the most widely used materials in the aerospace industry. This class of alloys owes their good mechanical properties to the presence of small dispersoid $\mathrm{Al}_{2} \mathrm{Cu}$ particles in its microstructure, $<0.01 \mu \mathrm{m}$, which impart mechanical strength to the material through a precipitation hardening mechanism. ${ }^{1}$ However, $\mathrm{Cu}$ also precipitates in the form of bigger $\mathrm{Cu}$-rich intermetallics forming small galvanic cells and rendering the alloy susceptible to localised corrosion. ${ }^{1}$

In industry, the classical treatment used to protect $\mathrm{Al}$ alloys from corrosion involves the application of a chromium oxide layer obtained either by anodisation or through chemical conversion procedures..$^{2-7}$ According to

\footnotetext{
*e-mail: hgdemelo@usp.br
}

the literature, the presence of leachable $\mathrm{Cr}^{6+}$ in the composition of the chromate layer guarantees corrosion protection to the alloy through a self-healing mechanism where these species diffuse to weaker spots of the layer recomposing its protective properties due to the precipitation of $\mathrm{Cr}_{2} \mathrm{O}_{3}{ }^{2,3,6,8,9}$ Although very satisfactory from the corrosion protection point of view and also as paint adhesion promoter, the use of chromate layers to protect alloys has been subjected to severe control by governmental authorities due to their hazardous effect to human health and to the environment.

The situation sketched above has led to the development of considerable efforts, made either by the industry or by research groups, to find an adequate nontoxic replacement for chromate conversion coatings for corrosion protection of Al alloys. ${ }^{1,3,10-25}$ Amongst the alternative pre-treatments one of the most promising involves rare earth metals, particularly Ce..$^{1,3,16-25}$ Cerium 
conversion layers ( $\mathrm{CeCL}$ ) on $\mathrm{Al}$ alloys started to be investigated in the mid 80's by Hinton and co-workers. ${ }^{16}$ In the beginning of the studies the main drawback was the excessive time for the layer precipitation ranging from several hours to a few days, this was partially overcome by the addition of $\mathrm{H}_{2} \mathrm{O}_{2}$ to the conversion bath, reducing the treatment time down to a few minutes. ${ }^{26}$

Although promising CeCL has not proved yet to be a feasible replacement for chromium conversion layers on $\mathrm{Al}$ alloys. For this reason, in the reviewed literature a wide variation on the conversion bath composition has been detected, with different $\mathrm{Ce}$ ions sources and acidifying agents. ${ }^{1,3,16-25}$ Also different surface pre-treatments have been applied to the $\mathrm{Al}$ alloys prior to the conversion treatment. Nevertheless, some of them are very complex and laborious to be used industrially, ${ }^{17-19,21,23}$ or either are proprietary of the aircraft industry. ${ }^{1,25}$

One of the main questions on the CeCL formation mechanism is about the role played by $\mathrm{Cu}$ particles and $\mathrm{Cu}$-rich intermetallics in the process. In the literature a main role is ascribed to the presence of the latter to the nucleation process due to the intense cathodic activity in the vicinity of these precipitates. ${ }^{1,22}$ Recently Campestrini ${ }^{3}$ has presented evidences that the presence of small $\mathrm{Cu} / \mathrm{Cu}$ oxide particles distributed all over the alloy surface would be the responsible for the precipitation of a uniform CeCL.

Electrochemical impedance spectroscopy (EIS) has been largely used to characterise conversion coated $\mathrm{Al}$ alloys. ${ }^{2-5,12,15,21,23,24,26}$ However, only few works have used EIS to characterise $\mathrm{Al}$ alloys coated with $\mathrm{CeCL},{ }^{21,23,24}$ moreover in all of these works the use of EIS was mainly aimed to extract impedance values upon immersion of the converted samples in the electrolytic solutions. Mansfeld and co-workers ${ }^{17-19}$ have also used EIS to investigate the corrosion behaviour of $\mathrm{Al}$ alloys covered with $\mathrm{Ce}$ conversion coatings, however, it seems that the results obtained by these authors are more linked to the thickening of the $\mathrm{Al}$ oxide layer than to the presence of a CeCL itself. ${ }^{20}$

In this work the electrochemical behaviour of Al Alloy 2024-T3 (AA2024) covered with a CeCL was investigated in $0.5 \mathrm{~mol} \mathrm{~L}^{-1} \mathrm{NaCl}$ solution using polarisation curves and EIS. The influence of some pre-treatments in the surface $\mathrm{Cu}$ content, prior to the immersion in the conversion bath, and its influence on the formation of the $\mathrm{CeCL}$ are discussed on the basis of SEM and EDX analysis. Finally, the microstructure of the CeCL was investigated by SEM.

\section{Materials and Methods}

The AA2024 used in this work was supplied by a Brazilian industry as sheets with dimensions of $(26 \times 10 \mathrm{x}$
$0,1) \mathrm{cm}$. This alloy has a high $\mathrm{Cu}$ content, typically between $3.8-4.9 \%(\mathrm{wt} \%)^{3}$

For the conversion procedure, the material, in the asreceived form, was cut from the original sheets in samples of $(4 \times 5) \mathrm{cm}$, which were vigorously washed with soap and tap water before being thoroughly washed with distilled water, alcohol and acetone and dried in hot air. The samples were held into the conversion bath by a polymeric string.

Prior to immersion in the conversion bath the samples were submitted to one of the following pre-treatments: $\mathbf{T} 1$ - Etched in $0.5 \mathrm{~mol} \mathrm{~L}^{-1} \mathrm{NaOH}$ solution during $120 \mathrm{sec}$; $\mathbf{T} 2$ - Etched in $0.5 \mathrm{~mol} \mathrm{~L}^{-1} \mathrm{NaOH}$ solution during $120 \mathrm{~s}$, and attacked in $0.5 \mathrm{~mol} \mathrm{~L}^{-1}$ acetic acid (HAc) solution during 300 sec; T3 - Grinded with 400 and 600 silicon carbide paper, polishing with diamond paste $(1 \mu \mathrm{m})$ and attacked in $0.5 \mathrm{~mol} \mathrm{~L}^{-1} \mathrm{HAc}$ solution during $300 \mathrm{sec}$; T4 - Grinded with 400 and 600 silicon carbide paper, polishing with diamond paste $(1 \mu \mathrm{m})$, etched in $0.5 \mathrm{~mol} \mathrm{~L}^{-1} \mathrm{NaOH}$ solution, and attacked in $0.5 \mathrm{~mol} \mathrm{~L}^{-1} \mathrm{HAc}$ solution during $300 \mathrm{sec}$.

After the last pre-treatment step, some samples were either vigorously washed with distilled water to remove the $\mathrm{Cu}$-rich smut present on their surface, or slightly washed to remove acid contamination prior to immersion in the $\mathrm{Ce}$ conversion bath. In the latter case the $\mathrm{Cu}$-rich smut was left on the alloy surface. Hereafter, adding a D after the pretreatment identification, like T2-D and T3-D, will identify mechanically desmutted samples. On the other hand, those samples from which the $\mathrm{Cu}$-rich smut was not removed will be identified by the addition of an $\mathrm{S}$ after the pretreatment symbol, for example T2-S and T3-S.

The composition of the conversion bath is given in Table $1,{ }^{13}$ and the time used to produce the CeCL was $2 \mathrm{~h}$.

Table 1. Cerium conversion bath composition

\begin{tabular}{ccc}
\hline $\mathrm{CeCl}_{3}$ & $\mathrm{H}_{2} \mathrm{O}_{2}$ & $\mathrm{H}_{3} \mathrm{BO}_{3}$ \\
\hline $0.01 \mathrm{~mol} \mathrm{~L}^{-1}$ & $0.009 \mathrm{~mol} \mathrm{~L}^{-1}$ & $0.00032 \mathrm{~mol} \mathrm{~L}^{-1}$ \\
\hline
\end{tabular}

All the electrochemical experiments were performed in a classical three electrodes cell, with the counter and reference electrodes being, respectively, a platinum grid and a silver-silver chloride $(\mathrm{Ag} / \mathrm{AgCl})$.

For samples with CeCL the electrochemical cell consisted of a glass tube glued to the $\mathrm{Al}$ converted sheet with acetate free silicone glue leaving an exposed area of $4.91 \mathrm{~cm}^{2}$. Prior to the electrochemical experiments the electrolytic solution was poured into the glass tube and the reference and counter electrodes put inside it. Adding distilled water to the electrolytic solution regularly restored its original volume and concentration. 
For experiments with bare AA2024 the sheet was cut into round samples, which, after the pre-treatment, was mounted in a Teflon sample holder leaving an exposed area of $1 \mathrm{~cm}^{2}$.

The chosen test solution for electrochemical tests was aerated $0.5 \mathrm{~mol} \mathrm{~L}^{-1} \mathrm{NaCl}$.

Potentiostatic measurements were performed using an electrochemical interface model SL $1287^{\circledR}$. Cathodic polarisation curves were obtained after two hours of immersion of the samples in the electrolytic solution, while anodic ones were initiated only after Ecorr stabilisation. All the curves were obtained in potentiodynamic mode with a scan rate of $0.5 \mathrm{mV} \mathrm{s}^{-1}$.

For impedance experiments an S1 $1260^{\circledR}$ frequency response analyser was used. Impedance diagrams were obtained in the frequency range from $10 \mathrm{kHz}$ to $0.05 \mathrm{mHz}$, swept logarithmically, and with an acquisition rate of 10 points per decade. The AC sign perturbation amplitude was $15 \mathrm{mV}$ (rms).

SEM imaging was made with a Stereoscan $440^{\circledR}$ equipped with an Oxford Link Isis ${ }^{\circledR}$ EDX probe. The acceleration voltage used to perform EDX analysis was $20 \mathrm{keV}$, giving a penetration depth of approximately $1 \mu \mathrm{m}$. Quantitative elemental analysis was performed using internal standards of the equipment, and, to obtain the percent composition, results were normalised to give $100 \%$ of metals representative to the alloy composition.

\section{Results and Discussion}

\section{SEM and EDX analysis}

Table 2 presents the surface $\mathrm{Cu}$ content, obtained by EDX, for AA2024 samples submitted to pre-treatments T1, T2-D and T2-S. For the sake of comparison the $\mathrm{Cu}$ amount of a polished sample is presented in the last column.

Table 2. Surface $\mathrm{Cu}$ content (at \%) on AA2024 submitted to different pre-treatments

\begin{tabular}{lcccc}
\hline Pre-treatment & T1 & T2 $-\mathrm{D}$ & T2 $-\mathrm{S}$ & Polished \\
\hline $\mathrm{Cu}(\mathrm{at} \%)$ & $7.3 \pm 0.1$ & $4.0 \pm 0.1$ & $4.6 \pm 0.2$ & $4.9 \pm 0.2$ \\
\hline
\end{tabular}

The results presented on Table 2 show an appreciable enrichment of $\mathrm{Cu}$ in alkaline etched samples, they also evidence the selective attack performed by HAc on the $\mathrm{Cu}$ of the alloy, since the $\mathrm{Cu}$ content of sample T2-D is lower than on the polished sample. Moffitt et al. ${ }^{28}$ studying elemental enrichment on AA2024 and AA7075 aluminium alloys surfaces from chemical cleaning, have detected a surface $\mathrm{Cu}$ enrichment in all the pre-treatments investigated. However, in the acid attack used here, as $\mathrm{Cu}$ is highly susceptible to $\mathrm{HAc}^{29}$ it would be preferentially dissolved during HAc treatment resulting in a lowering on surface $\mathrm{Cu}$ content in relation to untreated samples. This lowering can result in a better corrosion performance of the coated material, since it is thought that the presence of noble particles on the alloy surface underneath the coating is deleterious to its corrosion resistance, as it enhances the corrosion process due to galvanic action. ${ }^{28}$

The different surface $\mathrm{Cu}$ contents in samples T2-D and T2-S are likely due to the plating back of $\mathrm{Cu}$ ions dissolved from the AA2024 surface by the HAc attack, and is a result of their more noble potential in relation to the basis matrix. It is worth mentioning that the mechanism for $\mathrm{Cu}$ deposition proposed here is basically different from that proposed for classic acid pickling $\left(\mathrm{HNO}_{3}+\mathrm{H}_{2} \mathrm{SO}_{4}\right.$ solution). The latter is based on the dissolution of the $\mathrm{Al}$ matrix and deposition of the $\mathrm{Cu}$ particles released from the solid solution on the $\mathrm{Al}$ alloy surface. ${ }^{3}$ Indeed, SEM images and EDX analysis, not presented here, have shown an increased selective attack of the $\mathrm{Cu}$ from $\mathrm{Cu}$-rich intermetallics for increasing immersion time on HAc solution.

Table 3 presents Ce content (at \%) on CeCL obtained on Al samples submitted to different pre-treatments, the results points towards a strong influence of this variable on the formation of the conversion layer. ${ }^{22}$ The results presented in this Table were obtained by three EDS analysis over a large region of the samples, being thou, a mean value. Indeed, closer SEM observation of the whole converted surface has shown the presence of several imperfections on the CeCL as will be discussed later. Ce content for sample submitted to pre-treatment $\mathrm{T} 1$ are not given because the conversion layer formed on these samples peeled off after one day of exposure to the atmosphere.

Table 3. Ce content (at\%) on cerium conversion layers formed on $\mathrm{Al}$ alloy 2024 after different pre-treatments

\begin{tabular}{lccccc}
\hline Pre-treatments & T2-D & T2-S & T3-D & T3-S & T4-S \\
\hline Ce (at \%) & 13.2 & 23.7 & 9.0 & 6.5 & 15.3 \\
\hline
\end{tabular}

The first feature to be commented from the data presented in Table 3 is the influence of the mechanical treatment, namely polishing, on the growth of the CeCL. This feature is evidenced comparing the Ce content on samples submitted to T2-S and T4-S, and can be explained taking into account the mechanism involved in the CeCL precipitation. The two samples were submitted to the same chemical pre-treatments prior to their immersion on the conversion bath; however, sample T4-S was preliminarily grinded and polished prior to chemical attacks. In the literature it is almost a general consensus that the 
precipitation of the $\mathrm{CeCL}$ occurs due to $\mathrm{pH}$ increasing ${ }^{1,19-24}$ in the vicinity of the alloy surface caused by cathodic reactions, rendering less soluble the Ce oxide/hydroxides ${ }^{30}$ and leading to their precipitation near/at cathodic sites. For $\mathrm{Al}-\mathrm{Cu}$ alloys, the main driving force for the occurrence of interfacial electrochemical reactions is the potential difference between $\mathrm{Cu}$-rich particles and the $\mathrm{Al}$ matrix, with the latter functioning as anodic sites. The local $\mathrm{pH}$ increase at cathodic sites helps the whole process by dissolving the naturally formed $\mathrm{Al}$ oxide near them, and exposing the bare $\mathrm{Al}$ matrix to the electrolytic solution, forming stronger electrochemical cells and feeding the interfacial electrochemical reactions. In this sense, the presence of a less deformed oxide layer on polished samples would likely hinder the $\mathrm{Al}$ oxide dissolution process, affecting the rate of precipitation of the CeCL.

From the results presented in Table 3 some hypothesis about the role of $\mathrm{Cu}$ and $\mathrm{Cu}$-rich intermetallics on the nucleation and growth of CeCL can also be drawn. ${ }^{1,3,22}$ This subject is one of the most discussed in the scientific literature studying CeCL. However, although recognised the fundamental role played by these particles on the conversion layer formation process, their specific action on its growth mechanism is rather controversial.

Most of the published data about CeCL ascribes to the noble $\mathrm{Cu}$-rich intermetallics the role of nucleation point for the conversion layer. ${ }^{19-21,24,31,32}$ The micro corrosion cells formed between them and the nearby-deformed $\mathrm{Al}$ matrix would initially feed the cathodic reaction on the former, increasing the $\mathrm{pH}$, and giving rise to the precipitation of the cerium oxide/hydroxide..$^{30}$ At the same time $\mathrm{pH}$ rising enhances the dissolution of the naturally formed $\mathrm{Al}$ oxide, further feeding the electrochemical reactions. Once nucleated, the conversion layer would spread from the intermetallics to the whole matrix due to residual $\mathrm{pH}$ rising in a mechanism denominated "island growth". 1,33

In another growth model, Hughes et al. ${ }^{22}$ have suggested that deposition of the CeCL may involve thin $\mathrm{Cu}$ layers at the interface between the metal and the thin aluminium oxide layer beneath the hydrated cerium oxide layer. Recently, Campestrini, ${ }^{3}$ investigating the CeCL nucleation and growth on bare AA2024, verified that the presence of a $\mathrm{Cu}$-rich smut on the alloy surface gives rise to a faster growth and more uniform surface coverage by the conversion layer when compared to desmutted samples. Based on SEM and SKPFM measurements, the author ${ }^{3}$ proposed a mechanism for conversion layer growth which takes into account the preponderant role of deposited $\mathrm{Cu} /$ $\mathrm{Cu}$ oxide particles on the whole process. In this work ${ }^{3}$ it was also suggested that the $\mathrm{Cu}$ particles could also participate on the conversion layer nucleation process by reducing the activation barrier energy for cerium oxide precipitation, acting thou as heterogeneous nucleation site for the conversion layer growth mechanism.

The results obtained in the present work support the hypothesis about the important role played by $\mathrm{Cu}$-rich smut on the CeCL nucleation process. ${ }^{3}$ Indeed, in all the experiments performed, a much higher Ce content was detected on conversion layers obtained on smut-covered samples when compared to desmutted ones. This feature becomes evident comparing the Ce content on samples T2-S and T2-D presented on Table 3.

As early as 1987, Arnott et al..$^{34}$ investigating cationic film-forming inhibitors for the corrosion protection of AA 7075, have stressed the importance of the presence of a finely balanced state in order to obtain localised $\mathrm{pH}$ conditions leading to cation oxide or hydroxide film precipitation, while dissolving the aluminium oxide. This feature would be a result of competitive chemical and diffusion processes, and would explain the dependence in the protection degrees attained by the studied alloy, 7075, with the different types of inhibitors investigated. Indeed, the presence of finely dispersed $\mathrm{Cu}$ particles on the alloy surface would rise the $\mathrm{pH}$ all over it, thou creating ideal conditions for a uniform dissolution of the oxide layer and precipitation of the CeCL, as found here and proposed by the other authors. ${ }^{[3,22]}$

Figure 1 shows some SEM micrographs obtained for a sample submitted to pre-treatment T2-S and immersed in the conversion bath during $2 \mathrm{~h}$. Together with the cracked dry-mud structure of the CeCL, the Figures put also in evidence some of the defects generally found in the conversion layers, like pits and Ce-impoverished and enriched zones.

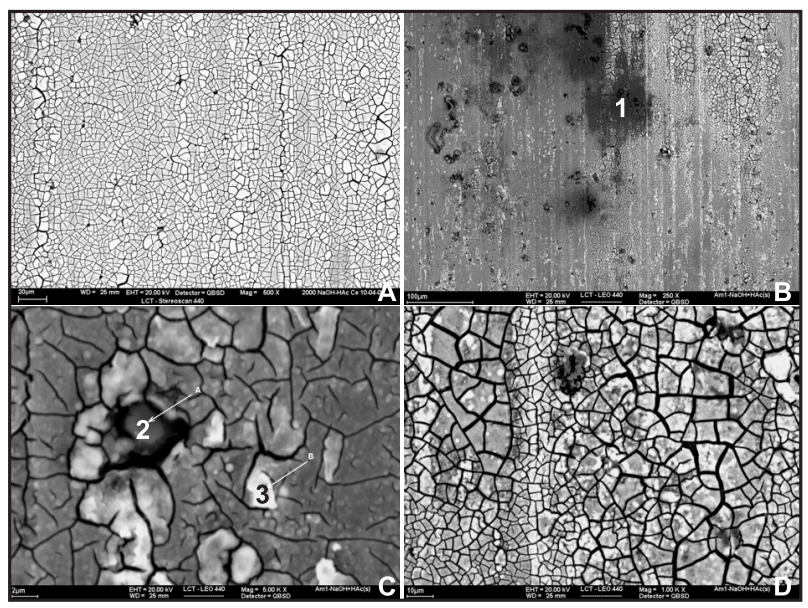

Figure 1. SEM micrographs presenting some particular features of the Ce conversion layer obtained on AA2024 (A) overview, (B) Ce impoverished region, labeled as 1, (C) pitted region, 2, and Ce-rich particles, 3, (D) heavily cracked region. Immersion time in the conversion bath: $2 \mathrm{~h}$ at $\mathrm{T}$ ambient. 
Regarding the dry-mud aspect of the conversion layer, presented in Figure 1(A), some authors have attributed it to the drying process applied after the samples have been taken out of the conversion bath, ${ }^{3}$ while other attributes this feature to the high precipitation rate of the layer above the intermetallics. ${ }^{1,21}$ The sample whose micrograph is presented in Figure 1 was not submitted to any specific drying procedure and at the present stage of this work we are not able to ascribe this microstructural feature to any particular phenomenon. However, we are prone to believe that the existence of this cracks bears no strict relation with the intermetallics since they are evenly distributed all over the surface.

The aspect of the CeCL presented in Figure 1(A) further confirms the role played by the small $\mathrm{Cu} / \mathrm{Cu}$ oxide particles plated on the alloy surface on the layer precipitation mechanism. They would form small nuclei distributed all over the surface that agglomerate giving to the conversion layer the appearance presented in Figure 1(A).

Figure 1(B) shows some Ce impoverished regions. EDX analysis of the region labelled as 1 in the Figure has shown a Ce content of $7.2 \%$ (at. \%) compared to a mean content of $23.7 \%$ (at. \%) for the whole layer. This result can be likely attributed to a deficient $\mathrm{Cu}$ plating at this region, leading to an inefficient $\mathrm{pH}$ rising, which, ultimately, will hinder the $\mathrm{Al}$ oxide dissolution and the $\mathrm{CeCL}$ deposition, giving rise to thinner or more uneven layers.

Two common features associated with the $\mathrm{CeCL}$ are depicted in Figure 1(C). The first one labelled as 2, represents a pitting, and the second, labelled as 3 , shows a Ce-rich region. The first feature has been attributed by some author ${ }^{20}$ to the high CeCL layer deposition rate at $\mathrm{Cu}$-rich intermetallics, in this way there would be not enough time to form a compact structure above them leaving an active corrosion cell in the conversion layer structure. Indeed, EDX analysis performed on the centre of this defect revealed strong Cu-related peaks. The latter feature would be associated with the CeCL precipitation mechanism itself, based on $\mathrm{pH}$ rising. With the high electrochemical activity near the intermetallics, ideal conditions for Ce oxide/hydroxide precipitation would be created, not only due to $\mathrm{pH}$ rising, but also due to an enhanced dissolution of the naturally formed $\mathrm{Al}$ oxide.

The heavily cracked regions depicted in Figure 1(D) are frequently ascribed to the existence of intermetallics due to their heavy cathodic activity. ${ }^{1}$ However this seems not to be the only reason due to the aspects already discussed above.

\section{Electrochemical investigation}

Figure 2 presents a comparison between anodic (A) and cathodic (B) polarisation curves for AA2024 with and without $\mathrm{CeCL}$ in $0.5 \mathrm{~mol} \mathrm{~L}^{-1} \mathrm{NaCl}$ solution. The anodic curves show that the presence of the conversion layer affects the corrosion potential, lowering it, however it does not change the pitting potential. This is in accordance with other authors' findings $\mathrm{s}^{33,34}$ and puts in evidence the nature of the corrosion inhibition afforded by the CeCL, which is due to the polarization of the oxygen reduction reaction as can be seen in Figure 2(B). ${ }^{33}$ In Figure 2(A) is also possible to verify that in the chosen solution the bare sample is in the active state, ${ }^{33}$ and, accordingly, its open circuit potential was characterised by oscillations due to pitting formation. It must also be emphasised that the time required for the corrosion potential to attain a stable value was much higher for conversion layer covered samples than for bare ones, the reasons for this behaviour have not yet been fully investigated; however, it seems that it can be linked to some modifications of the conversion layer characteristics, as will be discussed on the EIS experiments results.
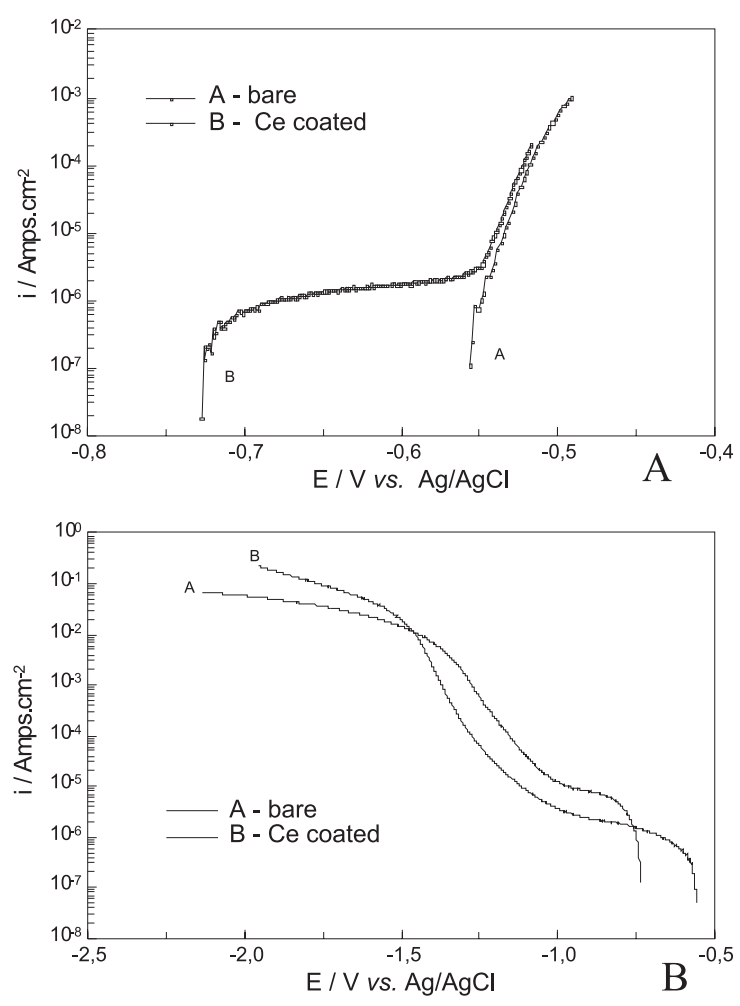

Figure 2. Anodic (A) and cathodic (B) polarization curves for bare [T2-D] and Ce conversion-coated [T2-S] AA2024 in $0.5 \mathrm{~mol} \mathrm{~L}^{-1}$ $\mathrm{NaCl}$ solution. Pre-treatment in brackets.

Figure 3 presents some impedance diagrams for bare AA2024 in $0.5 \mathrm{~mol} \mathrm{~L}^{-1} \mathrm{NaCl}$ solution. The diagrams are clearly composed by two capacitive loops one in the high to medium frequency regions and the other in the low frequency region. 
Regarding the high to medium frequency capacitive loop presented in Figure 3A, for Al alloys, some authors have attributed its existence to a series connection between the oxide barrier layer and the double layer capacity. ${ }^{35}$ Indeed, the diagram obtained after only five hours of immersion of the sample in the electrolytic solution presents a small high frequency shoulder, which could be eventually attributed to the separation of these two time constants. For longer immersion times this shoulder becomes less evident, and an increase in the phase angle in the medium frequency region is verified accompanied by a shift to lower frequency of the beginning of the whole loop. This behaviour is likely due to the destruction of the barrier layer by chloride ions and to the acceleration of the pitting process. Giving support to this hypothesis, the low frequency limit of the diagrams presented in Figure 3B assume a transmission line type impedance, which is typical for materials under pitting corrosion. ${ }^{19}$
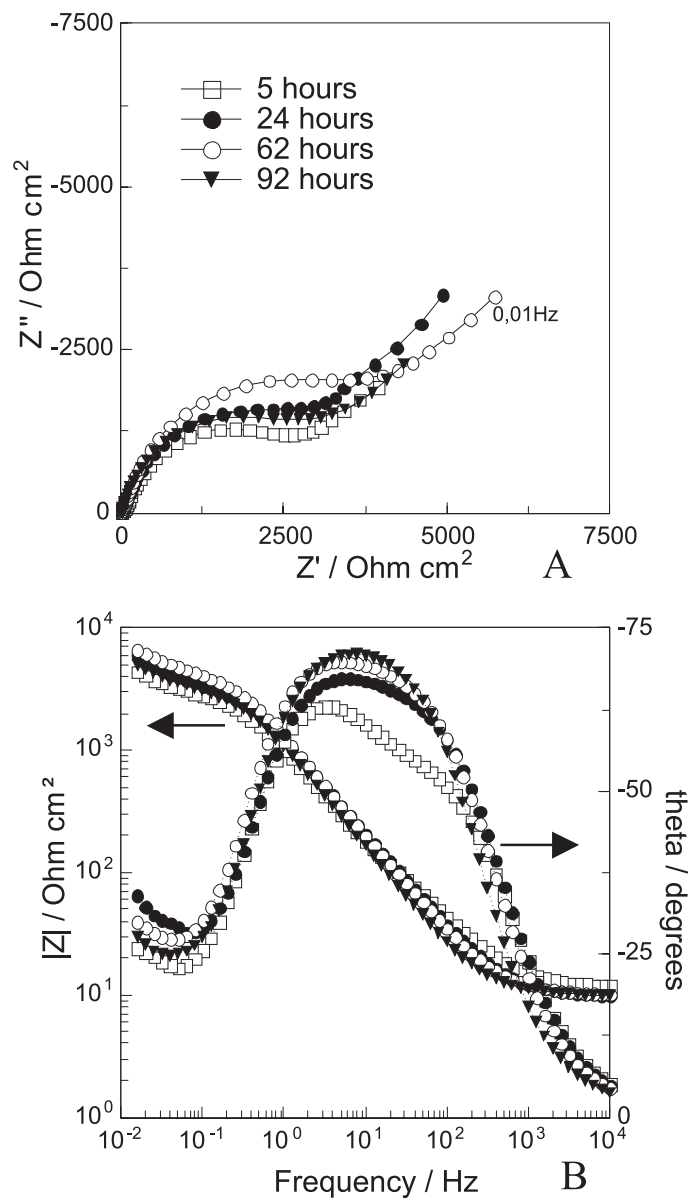

Figure 3. Impedance Nyquist (A) and Bode (B) diagrams for bare AA2024 in $0.5 \mathrm{~mol} \mathrm{~L}^{-1} \mathrm{NaCl}$ after different immersion periods in $0.5 \mathrm{~mol} \mathrm{~L}^{-1} \mathrm{NaCl}$ solution. Pre-treatment: immersion $5 \mathrm{~min}$ in $0.5 \mathrm{~mol} \mathrm{~L}^{-1} \mathrm{NaOH}$ followed by immersion $2 \mathrm{~min}$ in $0.5 \mathrm{~mol} \mathrm{~L}^{-1}$ acetic acid solution and mechanically desmutted [T2-D]. Pre-treatment in brackets.
Figure 4 presents impedance diagrams for bare and CeCL covered AA2024 in $0.5 \mathrm{~mol} \mathrm{~L}^{-1} \mathrm{NaCl}$ solution after the $92 \mathrm{~h}$ of immersion in the electrolytic solution. From the Nyquist plot is clear that the coated sample exhibits impedance values 3 to 4 times higher than that presented by the bare one. However the more striking differences on the electrochemical behaviour of both samples can be inferred from the analysis of the Bode phase angle plots, which are very different for both of them.

First of all, for the conversion-coated sample Bode diagram exhibits a high frequency phase angle, not present in the bare one. More detailed investigations performed by other authors on chromate conversion coatings ascribed the existence of this high frequency time constant to the presence of the coating itself, ${ }^{2-5}$ which we do believe is the same case for the CeCL investigated in this work. Moreover, if we associate the time constants present in the medium to low frequency range of both diagrams of Figure 4 to the same processes, namely, interfacial charge transfer phenomena, there is a clear displacement to lower frequency of the phase angle maximum for the conversion-coated
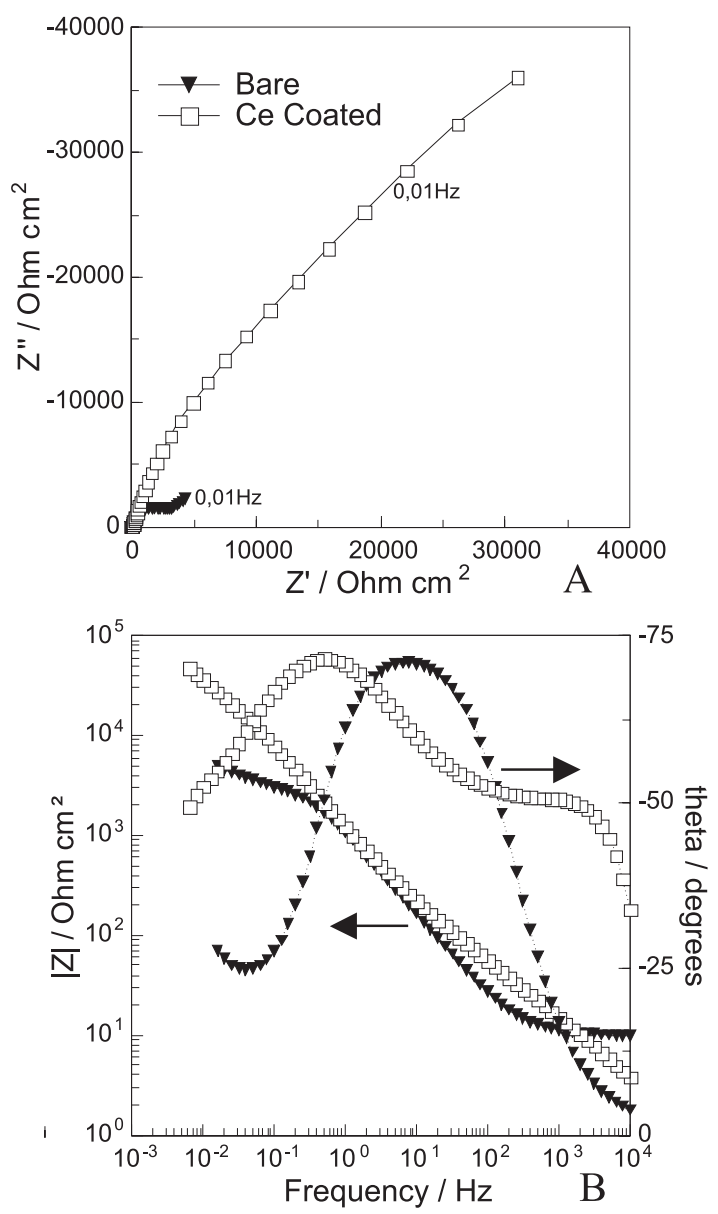

Figure 4. Impedance diagrams for bare [T2-D] and Ce conversioncoated [T2-S] AA2024 after $92 \mathrm{~h}$ of immersion in $0.5 \mathrm{~mol} \mathrm{~L}^{-1} \mathrm{NaCl}$ solution. Pre-treatment in brackets. 
sample, indicating the hindrance of these phenomena by the presence of the conversion layer. Moreover, the transmission line impedance present in the low frequency region of the diagram for bare samples does not appear in the one obtained from the conversion coated sample. This probably indicates that the time constant associated to pitting corrosion has been displaced to even lower frequencies due to the presence of the conversion layer.

Figure 5 presents impedance diagrams for $\mathrm{Ce}$ conversion-coated AA2024 for different immersion times in $0.5 \mathrm{~mol} \mathrm{~L}^{-1} \mathrm{NaCl}$ solution. Nyquist plots show an increase of the impedance for immersion times up to $130 \mathrm{~h}$ of immersion in the electrolytic solution. This is followed by a slow decrease of the impedance, which was registered up to 213 hours ( 8.9 days), pointing towards a high stability of the CeCL. The analysis of the diagrams shows that during this period Bode phase angle plots did not present any significant change in their shape, so we can suppose that no sharp change in the protection and corrosion mechanisms was observed during the whole immersion period.
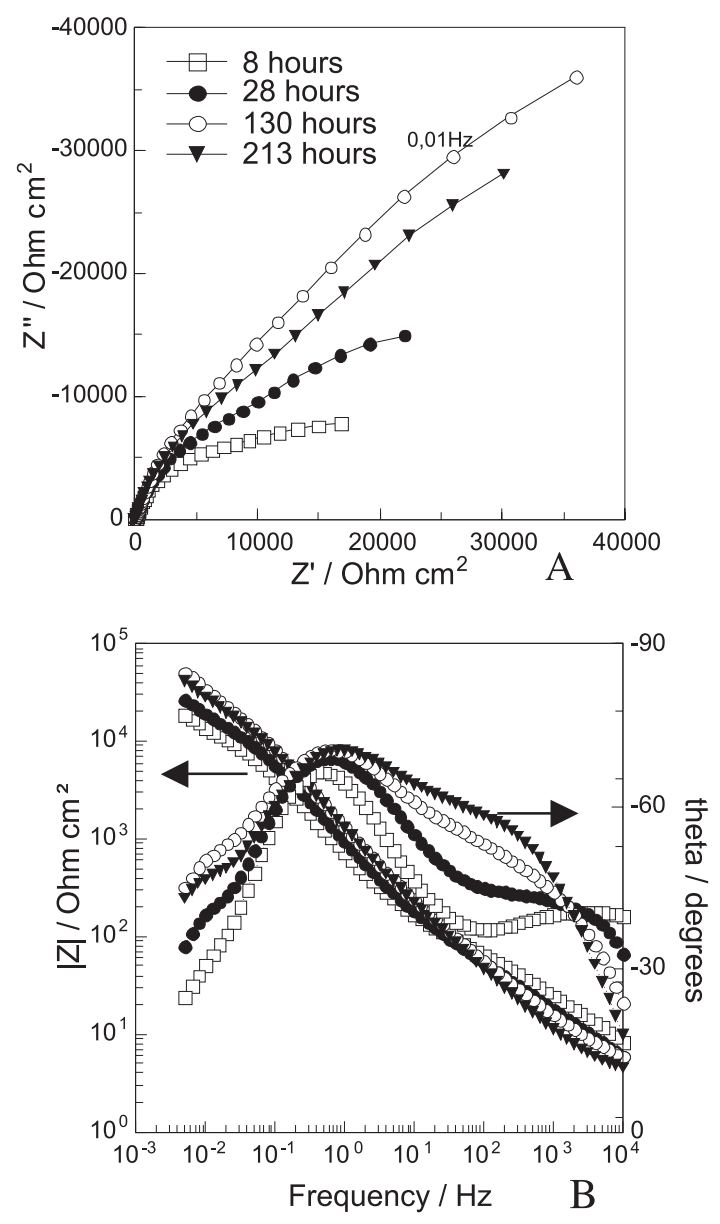

Figure 5. Impedance diagrams for Ce conversion-coated [T2-S] AA2024 in $0.5 \mathrm{~mol} \mathrm{~L}^{-1} \mathrm{NaCl}$ solution for different immersion times. Pre-treatment in brackets.
A closer analysis of the Bode diagrams presented in Figure 5 allow us to draw some hypothesis about the evolution of the interfacial phenomena for coated samples, if we take into account the hypothesis formulated above (Figure 4 analysis) about the origin of the time constants. Generally there is a displacement of the high frequency phase angle to lower frequencies for increasing immersion times, which is accompanied by an increase in the phase angles in the whole frequency range. The first feature can be eventually attributed to the progressive hydration of the conversion layer leading to the augmentation of its capacity, or either to some composition change suffered during the period. On the other hand, the latter hypothesis can be explained by an eventual blocking of the coating defects by some precipitates, maybe corrosion products that would hinder the progression of the corrosive attack.

Comparing the diagrams presented in Figure 5 with those obtained by Campestrini et al. for bare chromate conversion coated AA2024 exposed to $3.5 \mathrm{wt} \% \mathrm{NaCl}, \mathrm{pH}$ $4,{ }^{2,3}$ it seems that the interfacial phenomena occurring with the samples covered with the CeCL upon immersion in neutral $0.5 \mathrm{~mol} \mathrm{~L}^{-1} \mathrm{NaCl}$ solution are more complex than those exhibited by the ensemble studied by those authors. In the results of Campestrini ${ }^{2,3}$ the existence of only one time constant in the medium to low frequency range was pointed, on the other hand, in the results presented in Figure 5 the presence of two time constants in the same frequency range can be envisaged. As already discussed, here and in Campestrini work, ${ }^{2,3}$ the high frequency region is ascribed to the conversion layer itself.

The differences found between the results presented in this work and those presented by Campestrini ${ }^{2,3}$ can be explained either by the $\mathrm{pH}$ differences between the two media, neutral and 4 , or by differences in the protective mechanisms of the two conversion layers. As a last remark, it must be emphasised that the hypothesis formulated above about the origin of the time constants for the conversioncoated sample are only preliminary. More detailed analysis must be performed using equivalent circuit simulations and must be published in a forthcoming paper.

Regarding the impedance values exhibited by conversion-coated AA2024 samples, it must be said that it is much lower than those exhibited by other authors for $\mathrm{Al}$ alloys covered with $\mathrm{CeCL},{ }^{19,21,23,24}$ however they are comparable with the values obtained by Campestrini ${ }^{3}$ for bare chromate conversion coated AA2024 in $\mathrm{NaCl}$ solution. Moreover, for the sake of simplicity, we have deliberately chosen a conversion procedure simple to apply in order to allow us to verify the influence of some parameters on the conversion layer quality. Experiments are been performed in order obtain better quality conversion coating and also 
to verify the influence of parameters like $\mathrm{pH}$, cerium salt types and $\mathrm{H}_{2} \mathrm{O}_{2}$ concentrations on the microstructural characteristics and corrosion performance of converted samples.

\section{Conclusions}

The microstructural features and the electrochemical behaviour of AA2024 coated with CeCL were investigated using, respectively, SEM-EDX analysis and EIS. EDX results have evidenced the important role played by plated $\mathrm{Cu}$ cathodic particles on the conversion layer growth mechanism, which is based on Ce oxide/hydroxide precipitation due to local $\mathrm{pH}$ rising at the metal/solution interface. It was also shown that HAc attack of the alloy reduces the surface $\mathrm{Cu}$ content and leads to a distribution of a plated surface $\mathrm{Cu}$-rich smut that apparently helps the precipitation of the conversion layer.

For conversion-coated samples EIS results have shown an initial increase of the impedance values, followed by an almost stable behaviour up to 8.9 days of exposure to the electrolytic solution pointing towards a quite stable behaviour of the layer. Moreover, small evolution on the Bode phase angle diagrams were observed during this period indicating that some changes may be occurring in the conversion layer during the period.

Finally, polarisation curves have evidenced the cathodic nature of the corrosion protection afforded by the CeCL to the AA2024 matrix.

\section{Acknowledgements}

The author H.G. de Melo is thankful to FAPESP, São Paulo state (Brazil) research-financing agency, by the financial support to this project, and the author J.F.W. de Castro for the grant given by the same agency. L.E.M. Palomino is thankful to $\mathrm{CNPq}$, Brazilian research financing agency, for the grant.

\section{References}

1. Hughes, A.E.; Taylor, R.J; Hinton, B.R.W.; Wilson, L.; Surf. Interface Anal. 1995, 23, 540

2. Campestrini, P.; van Westing, E.P.M.; de Wit, J.H.W.; Electrochim. Acta 2001, 46, 2631

3. Campestrini, P.; PhD Thesis, TU Delft, The Netherlands, 2002

4. Goemine, G.; Terryn, H.; Vereecken, J.; Electrochim. Acta 1995, 40, 479 .

5. Goemine, G; Terryn, H.; Vereecken, J.; Electrochim. Acta 1998, $43,1829$.

6. Ilevbare, G.O.; Scully, J.R.; J. Electrochem. Soc. 2001, 148 , B196
7. Khobaib, M.; Reynolds, L.B.; Donley, M.S.; Surf. Coat. Technol. 2001, 140, 16.

8. Magalhães, A.A.O; Margarit, ICP.; Mattos, O.R.; Electrochim. Acta 1999, 44, 4281.

9. Akiyama, E.; Markworth, A.J.; McCoy, J.K.; Frankel, G.S.; Xia, L.; McCreery, R. L.; J. Electrochem. Soc., 2003, 150, B83.

10. Cohen, S.M.; J. Coat. Technol. 1996, 68, 73

11. Yang, X.F.; Tallman, D.E; Gelling, D.J; Bierwagen, G.P.; Kasten, L.S; Berg, J; Surf. Coat. Technol. 2001, 140, 44

12. Buccheit, R.G.; Cunningham, M.; Jensen, H.; Kendig, M.W.; Martinez, M.A; Corrosion 1998, 54, 61.

13. Xingwen, Y.; Chunan, C.; Zhiming, Y.; Derui, Z.; Zhongda, Y.; Mater. Sci. Eng. 2000, A284, 56.

14. Kasten, L.S.; Grant, J.T.; Grebasch, N.; Voevodin, N.; Arnold, F.E.; Donley, M.S.; Surf. Coat. Technol. 2001, 140, 11.

15. Yang, X.F.; Tallman, D.E.; Gelling, V.J.; Bierwagen, G.P.; Kasten, L.S.; Berg, J.; Surf. Coat. Technol. 2001, 140, 44

16. Hinton, B.R.W.; Arnott, D.R.; Ryan, N.E.; Metals Forum 7 1984, 211

17. Mansfeld, F.; Wang, Y.; Shih, H.; J. Electrochem. Soc. 1991, 138, L74.

18. Mansfeld, F.; Wang, Y; Shih, H; Electrochim. Acta 1992, 37, 2277.

19. Mansfeld, F.; Wang, Y; Mater. Sci. Eng. 1995, A198, 51.

20. Hughes, A.E.; Gorman, J.D.; Paterson, P.J.K.; Corros. Sci. 1996, 38, 1957.

21. Xingwen, Y.; Chunan, C.; Zhiming, Y.; Derui, Z.; Zhongda, Y.; Mater. Sci. Eng. 2000, A284, 56.

22. Hughes, A.E.; Hardin, S.G.; Wittel, K.W.; Miller, P.R.; Proceedings of the NACE Meeting: Corrosion/2000, Research topical Symposium: Surface Conversion of Aluminum and Aluminum alloys for Corrosion Protection, Orlando, USA, 2000.

23. Xingwen, Y.; Chunan, C.; Zhiming, Y.; Derui, Z.; Zhongda, Y; Corros. Sci. 2001, 43, 1283.

24. Dabalà, M; Armelao, L; Buchberger, A; Calliari I; Appl. Surf. Sci. 2001, 172, 312.

25. Fahrenholtz, W.G.; O’Keefe, M.J.; Zhou, H.; Grant, J.T.; Surf. Coat. Technol. 2002, 155, 208.

26. Wilson, L; Hinton; B.R.W.; Patent WO 1988, 88/06639

27. Terryn, H; Goeminne, G.; Schram, T.; Franquet, A.; Vereecken, $\mathrm{J} . ;$ Proceedings of the $7^{\text {th }}$ International Symposium on Electrochemical Methods on Corrosion Research, Budapest, Hungary 2000, Key Note N. 100.

28. Moffitt, C.E.; Wieliczka, D.M.; Yasuda, H.K.; Surf. Coat. Technol. 2001, 137, 188

29. Schweitzer, P.A.; Corrosion Resistance Tables, $2^{\text {nd }}$ ed., Marcel Dekker, Inc.: New York, 1986.

30. Pourbaix, M.; Atlas of Electrochemical Equilibria in Aqueous Solution, NACE, Houston: TX, USA, 1974. 
31. Sun, X.; Thomson, G.E.; Furneaux C.; Proceedings of the Aluminium Surface Science and Technology, Manchester, UK 2000, 515.

32. Aldykiewicz Jr.,A.J.; Davenport, A.J.; Isaacs, H.S.; J. Electrochem. Soc. 1996, 143, 147

33. Hinton, B.; Hughes, A.; Taylor, R.; Henderson, M.; Nelson, $\mathrm{K}$.; Wilson, L.; Proceedings of the $13^{\text {th }}$ International Corrosion Congress (ICC), Paper 337. Melbourne, 1996.
34. Arnott, D.R.; Hinton, B.R.W.; Ryan, N.E.; Mater. Performance 1987, 42.

35. Aoki, I.V.; Bernard, M.-C.; Cordoba de Torresi, S.I.; Deslouis, C.; de Melo, H.G.; Joiret, S.; Tribollet, B.; Electrochim. Acta 2001, 46, 1871.

Received: February 14, 2003

Published on the web: August 8, 2003

FAPESP helped in meeting the publication costs of this article. 